\title{
Narrative, Memory and Practice: Tensions and Choices in the Use of a Digital Artefact
}

\author{
Siân E. Lindley ${ }^{\mathrm{a}}$, Dave Randall ${ }^{\mathrm{b}}$, Wes Sharrock ${ }^{\mathrm{c}}$, \\ Maxine Glancy ${ }^{d}$, Nicola Smyth ${ }^{d}$ and Richard Harper ${ }^{a}$ \\ ${ }^{\mathrm{a}}$ Microsoft Research \\ Cambridge \\ $7 \mathrm{JJ}$ Thomson Avenue \\ Cambridge, CB3 OFB \\ +44 (0)1223 479\{881;824\} \\ \{sianl; r.harper\} \\ @ microsoft.com \\ ${ }^{b}$ Department of Sociology \\ Manchester Met. \\ University \\ Geoffrey Manton Building \\ Manchester, M16 5LL \\ +44 (0)1612473037 \\ d.randall \\ @mmu.ac.uk \\ ${ }^{\mathrm{C} S}$ chool of Social \\ Sciences \\ University of Manchester \\ Oxford Road \\ Manchester, M13 9PL \\ +44 (0)1612752510 \\ wes.sharrock \\ @man.ac.uk
}

\author{
${ }^{\mathrm{d}} \mathrm{BBC}$ Research \& \\ Innovation \\ London, W12 9PL \\ \{maxine.glancy; \\ nicola.smyth\} \\ @bbc.co.uk
}

\begin{abstract}
This paper reports on research into the use of SenseCam, a wearable automatic camera. Household members were given multiple SenseCams to enable an exploration of how the device would be used in the context of everyday life. We argue that understanding the 'small stories' created by household members based around SenseCam images requires us to pay attention to a complex amalgam of issues. These pertain to narrative, memory and practice in and through both the 'sites of expression' of such work - the topics that are selected for recall - and performativity - the occasions upon which narratives are constructed and the elaborations of identity that are entailed. Finally, we consider how the varied uses of SenseCam that emerged have implications for technologies relating to lifelogging and user-generated content.
\end{abstract}

\section{Categories and Subject Descriptors}

H.5.m [Information Systems]: Information Interfaces and Presentation - miscellaneous.

\section{General Terms}

Design, Human Factors.

\section{Keywords}

User-generated content, lifelogging, family, grandparents, children, storytelling, identity, mundane, everyday, SenseCam, mobile, wearable, passive, automatic, camera, photography.

\section{INTRODUCTION}

Recent years have seen an explosion in the sheer amount of memorial material - photos, videos, text etc. - available to people to use as they will. Several consequences follow from

(C) The Author 2009.

Published by the British Computer Society this, one of which is the likelihood of a shift in practices relating to what we will call 'reconstruction narratives'. In other words, the ways in which we piece together information from the past, in order to create some plausible narrative about what has happened, is altering. Technological changes herald changes to narrative structure, to the role of the narrator, and specifically, to rights over storytelling. In particular, the emergence of new and multimedia artefacts that can act as resources in the construction of narratives have potential ramifications for the 'small stories' that are told as part of everyday life. In this paper, we will consider the use of one such artefact, SenseCam, and how the ways in which it was used have implications for technologies that are concerned with the creation of user-generated content (UGC) and lifelogging.

Narrative here is understood as a set of choices around whether, when and how to construct a story. This may seem obvious, but some rather difficult arguments about 'identity' and 'reality' are seemingly implicated in this simple observation. We have seen, for instance, with Derrida and his (in)famous observation, 'il n'ya pas hors de texte' (usually translated as 'there is nothing outside the text'), that narrative has come to mean an indeterminacy of 'meaning' associated with the death of the author and the associated decline of authorial authority. Other writers (for instance, see Shirky [23]) have noted that the digitisation of narrative collapses the distinction between 'producer' and 'consumer', hence democratising authority and expertise. Thus, UGC has a role to play in the weakening of the 'authoritative' account. These considerations of indeterminacy have been applied equally forcefully in postmodern arguments about 'identity'. Here, the implication of a single entity that constitutes continuity and coherence amongst the parts of a human life is seen as fictional. It is replaced by views of 'identity' as contingent, polysemic and as a discursive construction. Identity becomes a matter of narrative, where narratives have no fixed and essential character or content. Many alternative narratives are always possible, and we will demonstrate here how these can be linked with the various stages of family life and their associated social identities.

If narrative can be construed in the way we suggest, as being to do with how we tell stories on specific occasions, then memory in a digitalised universe implicates decisions about whether and how to store those stories, and with what purposes in mind. The existing literature on memory, which extends at least back to 
Ebbinghaus [5], runs along two fault lines. Firstly, there are issues around whether memory should be conceived of as an individual 'mental' phenomenon or as a social accomplishment. Secondly, there are questions as to whether the interesting issues associated with memory are those to do with its fallibility, or those to do with the occasions of its display (see e.g. $[20,21]$ for a fairly thorough account of these issues). We take no side in this, at least in respect of the intellectual positions that lie behind these interests. Indeed, we would not be the first (see [19]) to argue that understanding memory requires us to understand both its individual and its collective dimension.

While psychologists [e.g. 1] have examined memory chiefly as a cognitive construct, sociological work has mainly emphasised the idea of 'collective' memory and the way that it functions, for instance, in rite and ritual. Notions of 'family' memory [8, 9], 'collective memory', 'social memory', 'habit' memory [3], public representation ([2]) etc. seem to emphasise broadly two themes. The first is the site of expression through which memories are conveyed. This pertains to the topics that are recollected and how these relate to notions of tradition and modernity. The second has to do with performative elements, or in other words, how memories are enacted in conversation, stories, photos, and so on (see [17, 18]). Zerubavel [26], for example, notes that we learn which topics are worthy of recounting, and how to go about this. He suggests that memory is:

'a subtle process that usually happens rather tacitly; listening to a family member recount a shared experience, for example implicitly teaches one what is considered memorable, and what one can actually forget' (p. 87).

In this paper we will consider how a digital artefact, a lifelogging tool called SenseCam, was used in the construction of narrative and the expression of identity. SenseCam is an automatic wearable camera and, as such, takes photos on a continuous and passive basis while turned on. We would expect this artefact to be used like any other storytelling resource, in that memories triggered through SenseCam photos will be evoked in and through a site of expression. In other words, although all aspects of life may be recorded, only certain of them will be reconstructed in narrative form, and this articulation will often be in the context of a broader topic or theme. Additionally, these narratives will be organised and produced performatively, being selected for individual and collective significance. To put it another way, we are interested in how 'small stories', as they are told by ordinary people, come to be the memorial and narrative of the artefacts that they come to use.

As already alluded to, SenseCam is an artefact unlike those that our participants had prior experience of. A camera that is worn and that takes photos automatically has a number of implications for the ways in which photos are experienced. For example, narratives can be based on photographic content that would not normally be captured. Further, and resonating with the weakening authorial voice already mentioned, photos are not necessarily 'owned' by any one individual; there is no photographer. Finally, SenseCam photos have certain qualities, in that they allow individuals to revisit their own world, but simultaneously make that world somehow strange. It has been previously reported that the combination of a fish-eye lens, an unusual vantage point and the seemingly objective representation of time depicted within SenseCam image streams, combine to give a sense of defamiliarisation, to promote reflection $[10,11]$ and result in different values being realised in the resultant photos [15].

In this paper, we report on a study in which SenseCams were given to people who live together, either as families or as couples, with the aim of exploring how the device would be used in the context of home and family life. This contrasts with prior work on the device, which has largely focused on its use by individuals [e.g., 6, 10,12, 13, 16, 22]. The study then, stands as part of a continuing exploration of the socio-technical, and one which is predicated on something quite different to the problem-solution space normally occupied by studies of technology in working and organizational life. In this paper, we will explore notions of narrative, memory and practice relating to the use of SenseCam images. Our hope is that these modest results can be translated and made relevant to some of the developing themes of sociological research and HCI, and we will draw implications pertaining to lifelogging and the creation of UGC in particular.

\section{THE FIELD STUDY}

The broad aim of the study was to explore how lifelogging and data collection tools, including SenseCams, pedometers and energy meters, might be used in the context of everyday life. In particular, our initial research questions centred on how these technologies might lead users to reflect upon their daily lives and recount those reflections to others in the context of close relationships. The study took place over the course of one week, and began with an initial interview for which two of the authors visited the participants at home. During this session, SenseCam, its associated software and the other technologies provided were all demonstrated. Each household was also loaned a laptop, which was installed with software to support the download and viewing of SenseCam images. In an effort to alleviate any unspoken privacy concerns (none were expressed) it was made clear that images could be deleted from the laptops before they were returned to us. Our motivation was described as being an interest in if and how the equipment provided might be used in the context of the participants' daily lives, and it was emphasised that we were not concerned with gathering data about the participants themselves. After a week had passed, the researchers returned to discuss with the householders how they had used the technology provided.

\subsection{SenseCam}

SenseCam [12] is a wearable camera with a wide-angle lens. While turned on, it automatically takes photos at regular intervals and in its default mode will capture around 3000 images in a day. It also has a number of built-in sensors, including an accelerometer, a passive infrared sensor, a temperature sensor and a light sensor. Information recorded by these sensors, such as movement, is also used to trigger the taking of photos. In addition to an on/off switch, SenseCam has two buttons. The first of these triggers the deliberate taking of a photo, while the second causes the recording of images to be temporarily suspended. As shown in Figure 1, SenseCam has a lanyard and can be worn around one's neck. However, the form factor of the device also permits it to be stood up and positioned so as to capture images from a fixed vantage point. SenseCam itself does not have any means of displaying images back to the user; these must instead be downloaded onto a computer. Images that are imported together are saved in a specially created folder, and can be opened directly or viewed using a dedicated piece of software. This allows photos to be played back at varying speeds, and enables the viewer to bookmark and label sequences of interest. 


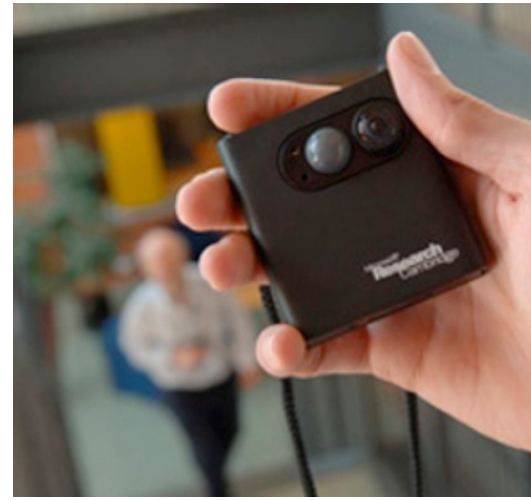

Figure 1. The SenseCam device used in this study

\subsection{Households}

Seven households took part in the field study, five of which were families with young children. Three of these lived in a village in Cambridgeshire and were interviewed as a group in one of the family's homes. The fourth lived near to Manchester and the fifth was based in London. The composition of these families was as follows.

The first Cambridgeshire family, whose house formed a base for the interviews, consisted of a lesbian couple and their two children, a girl aged 7 and a boy aged 1 . The second family consisted of husband, wife and two girls aged 7 and 4, and the third comprised husband, wife, a 10 year old boy and an 8 year old girl. Due to the age of the youngest children in the first two families, they were provided with three SenseCams between them, whereas the final family were given four. These families were interviewed together following previous research in which group discussions of SenseCam proved a fruitful means of understanding how the device had fostered reflection [10].

The family near Manchester consisted of a married couple and their two children aged 11 and 13, and the London-based family had a son aged 7 . This latter family were visiting their grandparents, who are in their early $60 \mathrm{~s}$, during the field trial period. These families were provided with four and three SenseCams, respectively.

The final two households each comprised a couple in their early $30 \mathrm{~s}$. These two couples were friends with one another and lived near Blackburn in the north of England. Each of these households was given two SenseCams each. Again, these participants were interviewed as a group.

\subsection{Data Analysis}

The discussions with the households about their use of SenseCam were transcribed and used in conjunction with field notes to identify emergent themes in the data. This was conducted by the first two authors independently. Some of the themes that surfaced, such as the way that participants oriented to the visual nature of SenseCam image streams, were fairly ubiquitous in the data and are reported elsewhere [15]. In contrast, others seemed more specific to certain participants within the sample. This paper explores some of the differences in the ways in which SenseCam images and other data (e.g. pedometer readings) were used by household members to reconstruct their experiences both for the researchers and for one another. The varying sites of expression through which this occurred will be presented first, followed by a consideration of the perfomative aspects of these narratives.

\section{SITES OF EXPRESSION}

As indicated above, we became interested in exploring how discussions of SenseCam images caused memories to be evoked in and through 'sites of expression', and how these differed across households. The following presents an analysis of some of the aspects of life were focused upon by our various participants. The data are organised into three themes: routine, playfulness, and a sense of family. Some of these, such as routine, were evident in all interviews, albeit made manifest in different ways. Others, such as playfulness, seemed to characterise certain participants' experiences of SenseCam, while being almost absent for others. Extracts from discussions both with and between the participants that relate to these three topics are presented below.

\subsection{Routine}

The subject of routine, and how this was depicted through SenseCam image streams, surfaced in our discussions with parents in particular. This is perhaps unsurprising; after all, a fundamental feature of daily family life is its utterly routine nature. However, the repetition made evident through SenseCam revealed a very distinctive division between adults and children. Children were consistently unimpressed by the device, as is shown in this extract from a discussion between the three Cambridgeshire family groups and an interviewer:

Mum: they weren't anything like as interested as I expected them to be, of course some of the images were rather blurry and they lost interest rather quickly

Researcher: was it boring ... did you find it boring ...

Son: $\mathrm{mmmm}_{\text {... }}$

2nd Mum: yes, our children lost interest quickly as well, and I think one of the reasons is that ... if you wear them all the time ... life is quite boring really ... there's a lot of images of me washing dishes and putting things on the line ... to be expected to look through all the different images to find that little [interesting] bit.

As a toy then, SenseCam failed to engage. The world of the child is one in which, arguably, things to be remembered are constituted in excitement - the unusual and the thrilling. In the absence of such occasions, the children in our sample were singularly unimpressed. As the 13 year old from Manchester put it:

We didn't actually do much this week. Although it was the school holiday, we didn't go anywhere ... I just hung around with my friends.

In contrast, for parents, and especially those with young children, the recovery of the mundane is an occasion for reflection on moral consequence:

Mum: ... we talked about the number of times we seemed to be sat round the kitchen table ...

2nd Mum: we noticed that too ...

Researcher: really?

Mum: yeah, we often put it [SenseCam] to one side rather than have it hanging around our necks, and that's what we found...

2nd Mum: ... and driving ... phenomenal ... driving is really boring ... it prompted us to get our bikes out, actually. 

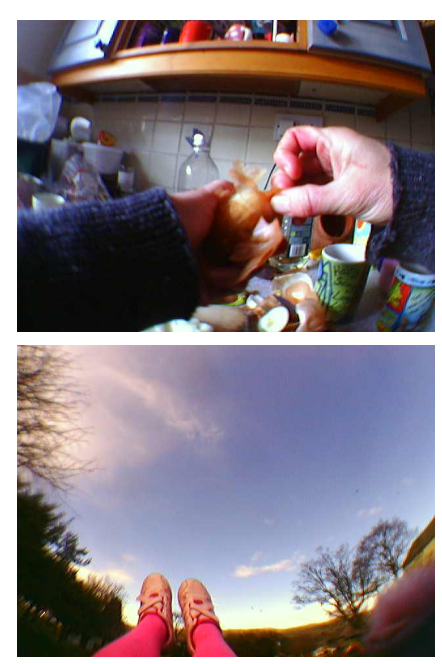

Figure 2. Family life as captured by SenseCam.

As this discussion continued, it was clear how reflections upon the routine were capable of evoking various emotions. That is, the various guilts and suppressed feelings concerning the mundane, even boring, nature of the everyday were thrown into sharp relief:

Mum: The thing that I noticed was how little time I spent playing with my children. I spend a lot of time looking at them, walking away from them, coming back to them, walking away from them. I'm obviously doing things. I'm on my feet all the time, but to sit down and play with them ... was really quite depressing..

2nd Mum: ... and you see how just getting out of the house takes twenty-five minutes ... and you have to get them to school.

Sometimes, these reflections seemed to prompt decisionmaking. The following discussion emerged around use of pedometers during the week in question:

Mum: ... I found it really interesting, because I know nothing about her day...

Dad: I noticed how incredibly sedentary I am ...

Mum: oh yeah, I'm at home and I clocked up 3,500 steps before breakfast ...

Dad: ... whereas I didn't do that much the whole day ...

Mum: ... but it did prompt you to go running several times, which you don't normally do.

Whether such decisions turn out to be permanent alterations in the daily routine, we cannot say, but these discussions do illustrate how the review of such data can occasion reflection on the nature of the mundane for parents in particular.

\subsection{Playfulness}

Family life is of course not all about monotony; it can also be an opportunity for play. While we had initially expected families with children to use SenseCam in a playful manner, in fact it was the young couples in our sample that were most proactive in trying to find fun ways in which to use the device. For example, one pair recorded images of each other while amusing themselves on a seesaw during an afternoon walk, and also attempted some time-lapse photography of themselves moving towards a tree (Fig. 3). As the young woman in question reported to us:

We went for a walk round the reservoir on Friday ... we hung it [SenseCam] on a tree and walked really slowly towards it and it was like it skipped bits it was like we'd jumped forwards ...
M's dead arty anyway so we were like walk dead slowly and see what happens ... on that walk as well, this makes me sound about ten, we found two trees that had fallen over and like a see-saw, so we sat on that and were jumping up and down, so $M$ 's are looking up the tree and mine are looking down.

The two couples also arranged to meet up during the week. This was partly encouraged by their participation in the field trial; we had suggested to all householders that they might use their SenseCams to gain multiple different perspectives during some kind of event. Interestingly though, the couples were the only participants to follow this up. They organised an evening in which they played board games and also computer games such as Guitar Hero, and positioned SenseCams around the room to capture different views (Fig. 4). In these cases, the overriding impression was one of playfulness and, by their own admission, the evening became progressively more chaotic, fuelled by the consumption of alcohol.
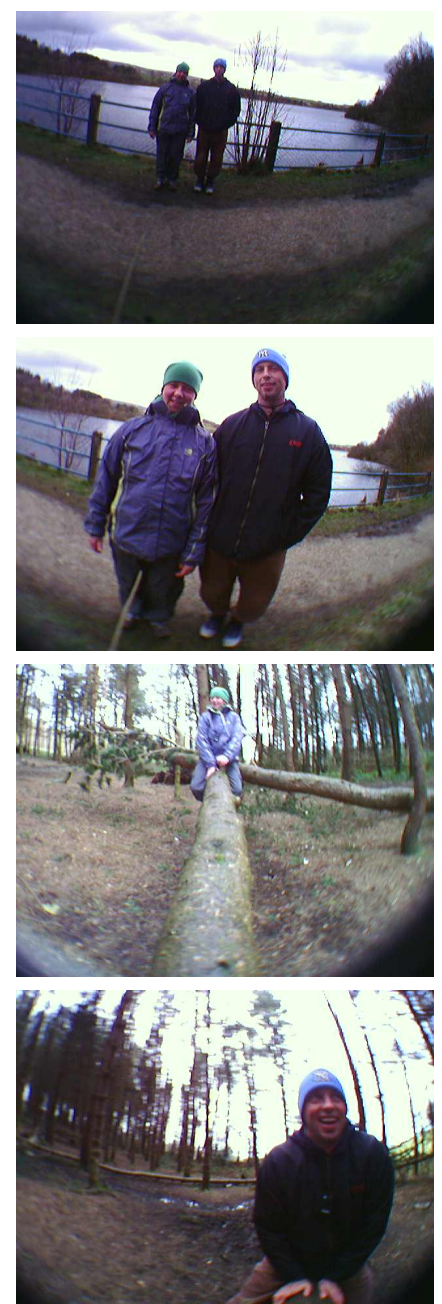

Figure 3. Images captured from a SenseCam hanging from a tree and while on a seesaw.

Wearing a SenseCam also seemed to provoke a degree of creativity in these participants, which might not normally have been expressed. The woman who was quoted above describing her walk not only positioned her SenseCam in unusual places, such as hanging from trees, but also chose to deliberately take pictures, featuring subjects that she would not usually capture:

This sounds really boring, but we went to Chester ... really beautiful like historic city, and there's loads of really nice doorways, you know really old beautiful doors with stained 
glass and stuff, and I used my SenseCam to take loads of pictures of different doorways which I never in a million years would have thought of doing ... I was walking round and I was like god that's really nice, that's really nice, and I thought well sod it I've got my camera round my neck, and cos it was there I used it ... that's an arty thing that I wouldn't normally have gone out and done.
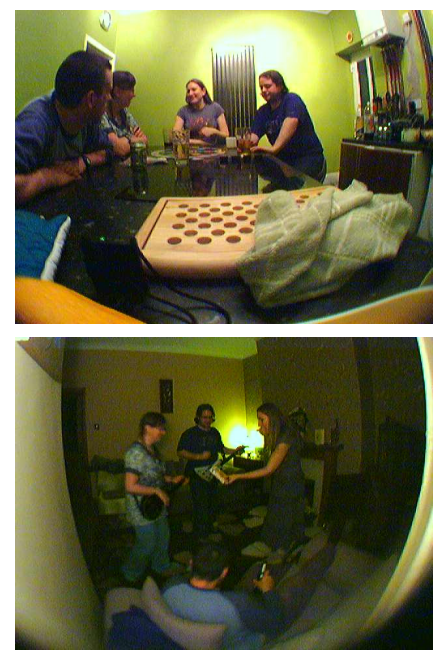

Figure 4. Images captured from SenseCams during an evening of game-play.
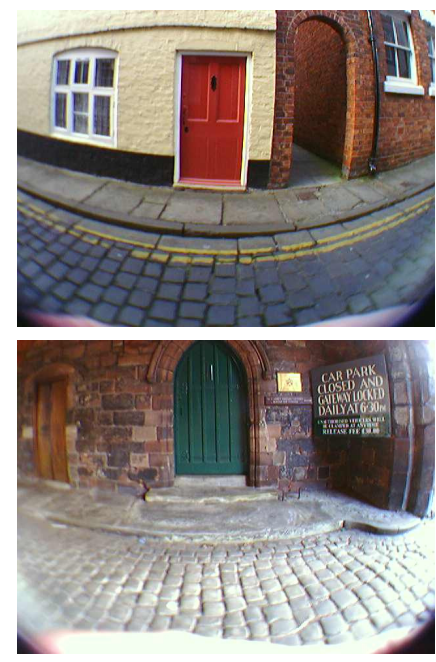

Figure 5. Images deliberately captured of doorways in Chester.

Further, and in findings that resonate with previous work [10], the candid nature of automatically captured SenseCam photos was also appreciated by these young couples. Reflecting the creativity described above, the pleasure derived from these photos was sometimes simply artistic, reflecting the unusual imagery:

Male: I prefer stuff like that, not like...

Female: ... posed

Male: ... yeah not posed, but not like perfect either, I just think you can find angles and perspective that you can't find ... I think there's something a bit more creative about it ... you get some really unexpected results.

In other cases however, enjoyment was derived from how photos of the mundane could be interpreted, especially when they seemed to say something about relationships with one another:

Did you not watch how you interact with each other as well, cos I found that interesting, like $M$, not consciously, but holds my hand when we're driving sometimes, and it kinds of made me go, oh how cute, you know just little things that you don't really notice.

For these couples then, the everyday became a trigger for narratives that pertained to intimacy and amusement. In stark contrast to the families, their experience with SenseCam led them to talk about playfulness, artistry and intimacy.

\subsection{The Sense of a Family}

If there is an evident difference between children and parents, between couples with young children and those without children, there is also in our data a distinctive way in which the two grandparents used SenseCam. In our view, these grandparents saw the images that SenseCam generated as being a record of the family, with their reflections creating a story around the family's history and the role of the various characters within it:

Granddad: I tended to hang behind ... I looked at $J$ [the grandson] when he was playing with the crabs ... P started to use his phone and I got curious about how long he was on the mobile phone and he was on the phone for at least 45 minutes, maybe an hour....

Gran: and I noticed the day before how often he was texting ...

Granddad: I was saying the other day that, if you had storage capacity ... and it was wireless so you could download it automatically and you could record your grandkids ... do you remember when you had just one camera ...

Gran: ... yeah, do you remember the Brownie camera, when you could take just eight photos

Granddad: and, you know, when you're sitting around telling a story, you know, 'do you remember when...', and you could just get it out ... the laptop.
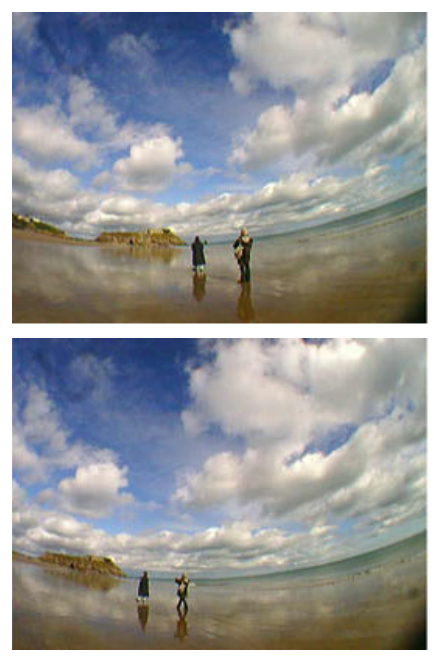

Figure 6. Images taken on a family walk.

In the following extract, the grandparents and the mother watch some SenseCam clips of her day together:

Mum: you see, when you run through it ... you see him [her son] fiddling with his Transformers ... he's at it all the time ... never stops ... and I'm just driving to Sainsbury's ... and then he puts them [some chocolate Easter rabbits] in a line and takes a picture of them, cos he remembered the SenseCam was there ... 
Mum: and then we're in the queue, waiting and waiting ... the 'enter' button in the Chip and Pin was stuck ...

Mum: you see, he packed the bags for me ...

Mum: I think we've got a clip of him doing his Easter egg hunt on Sunday...

[searches]

Gran: hmmm ...

Granddad: ahhh ...

Gran: he made a little Easter tree as well ... he got some twigs together and put em in a vase, then he just opened his eggs up ... it were lovely...

Granddad: ... ohhh, it's brilliant that bit ...

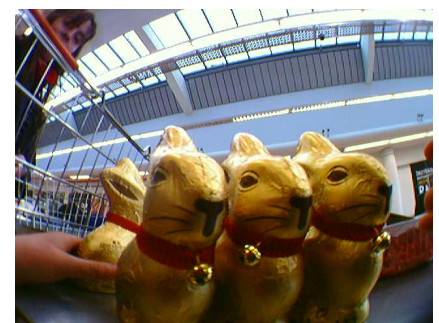

Figure 7. Image of Easter rabbits taken by a grandson's SenseCam at a supermarket.

What is evoked here is more than the sense of routine that we mentioned above, and more than the playfulness also described. This is evidently emotional work - work which locates and fixes the roles of family members and their evolving history.

\section{PERFORMATIVITY}

Performativity, with SenseCam, is almost entirely retrospective. The device is unique insofar as images are recorded automatically and so questions about its use become questions about selection (and as a result, attention shifts to retrospective composition of narrative). One of the features of SenseCam that was valued was its uncontrolled operation, allowing favourable contrast with other recording media such as cameras. Use of SenseCam eliminated the need for contrivance, for the setting up of recording occasions, and allowed for the capture and noticing of things that might otherwise have passed by unnoticed. The responsibilities of 'authorship', then, become almost entirely post-hoc, and the narratives that result, as we have suggested, are occasioned and produced in quite specific ways. We say 'almost', because these data also include examples of deliberate image capture, prompted by the presence of SenseCam itself (e.g. Fig. 5) or by the manipulation of a scene with SenseCam in mind (e.g. Fig. 7).

However, these examples were very much in the minority. What was apparent in all households was the way in which the retrospective viewing of SenseCam images became a vehicle for the production of stories pertaining to the significance of everyday life. Indeed, in some of the examples described above, we have seen how memories were interactionally produced as a resource for sharing family experiences, in much the same way as printed photos and albums can function [cf. 4, 7]. Our central point in this respect is that narrative construction and delivery is a skilled and collaborative activity. A capacity for narrative is commonplace, and people are generally capable of producing small stories in their everyday conversations to deliver news, update people, amuse them, and so forth. Even so, there is no intrinsic narrative potential in SenseCam images, nor are there externally imposed requirements such as thematic unity, continuity of sequence, comprehensibility of development, or exhibition of narrative arc - the production is almost always a joint one.

What also affects one's willingness to participate in the construction of the narrative, and what kind of narrative it might be, is the particular position one occupies in these networks of relationships and activity. The performances we observe as people recount their experiences to us, normally in the presence of other participants, reflect the identities they construct for themselves at these moments. Our data seem to show quite clearly that who one is in respect of family life or social network powerfully affects not only the use one will, or will not, put SenseCam to, but also the way in which one will subsequently talk about it. If SenseCam is little more than an encumbrance which intrudes upon the day, as it is for children, it is because their identities as children are produced out of a vivid sense of the world as either mundane or exciting. It sometimes, for busy parents, occasions reflection of a moral kind precisely because the family is a moral unit, one where questions such as, 'what kind of parent am I?', 'how boring or otherwise is my day and can I make it better?' and so on go into the production of an identity as busy parent. For young adults, without the encumbrance of children, it is a vehicle for celebrating relationships, more often than not in playful ways. Arguably, such relationships involve appreciably less concern for reflection on the mundane. For older people, especially those with grandchildren, reflections take a different form. They are, if you will, celebratory in a different way, reflecting the grandparents' position as custodians of family history.

The use or otherwise of SenseCam, in other words, was intimately connected with identity questions, with the record being interrogated for what it showed about the kinds of people that they, and those they associated with, were like. The 'kinds of people' issues were often of a characterological type, noticing things about oneself, such as that one is more grim and forbidding in dealing with the children than one imagines, or that a son-in-law is more engaged with business calls on his mobile than with others on a family outing. This can be glossed, as suggested, as associating with the 'stages' of family life in question, and the roles that individuals play within it.

\section{IMPLICATIONS}

SenseCam was originally inspired to be a tool to support lifelogging and to help fill gaps in memory [12]. Indeed, when considering memory as an individual cognitive construct, there is evidence to show that the review of SenseCam images can be beneficial, especially where memory is impaired [e.g. 12, 24]. However, if lifelogging devices are to be used more widely, a consideration of the social context of this use becomes necessary. In this paper we have focused less on the idea of cognitive memory, and have instead looked at SenseCam as an artefact used by families and couples to interactionally produce what might be considered social or collective memories. By doing so, we can consider a number of implications that will doubtless become relevant if lifelogging tools do become ubiquitous, starting with the way that our participants oriented to SenseCam photos.

One of the findings to emerge in this paper is the similarity between the narratives that we have described and those that might be grounded around typical photos [cf. 7]. If lifelogging tools are to become more widely available, their content is also likely to be used to support the reconstruction and sharing of experiences with others. Of course, in the context of the present study, it was improbable that SenseCam would actually be conceived of as a memory aid. There is little need to look back over a series of images to remember what has happened during 
a one-week period. However, the social and performative aspects of memory highlighted here underline the need to also consider how lifelogging tools can be designed to support reconstruction narratives in a social context. Indeed, we are not the first to place SenseCam in such a setting; for example, Fleck and Fitzpatrick [6] have also noted the usefulness of such a device to teachers, when reflecting with a mentor and learning from recent experiences.

It is also worth emphasising though, that the design of SenseCam does have certain consequences for the ways in which narratives are produced. The automaticity of the device and the resultant large number of images shifts the authorial voice to one that is almost wholly post-hoc; there is no sense of the 'decisive moment' with SenseCam. In reconstructing narratives then, it is left to the narrator to ascertain unifying themes and to identify the relevant image sequences. Thus, when devices capture data automatically, an obvious need for flexibility in dealing with the resultant data set arises. The user must be able to access appropriate images (we saw this in the example of a mother searching for an image of an Easter egg hunt), and may wish to flip between photos that pertain to similar themes but that are taken on different occasions. We have seen also how participants used SenseCam images not to give a blow-by-blow account of events as they unfolded, but to focus on what was interesting or important to them. Indeed, in some of the narratives reported above, there is little sense of what did actually happen; a sense of routine or playfulness emerges as an overarching theme, derived from insights taken from the SenseCam image stream as a whole. The current organisation of SenseCam images, which are simply grouped as those downloaded together, with the opportunity to bookmark sections, does not offer strong support for this type of narrative. Research is currently underway to explore how libraries of SenseCam images might be organised, events demarcated and similar occasions searched for [e.g. 13]. However, there remains little emphasis on seeking to understand whether these features actually support photo sharing and conversation. This seems an area worthy of much more exploration.

The analysis presented in this paper also makes obvious the way that different people frame their narratives in the context of very different themes. The varying sites of expression that we have discussed can be linked to social identity; children had little to say on the topic of SenseCam, while parents found it a prompt for deliberations of moral consequence, and grandparents used it as a lens through which to view the family. It is of interest then, to consider how one individual might orient and reorient to the same set of images over time, as a lifelog develops. Obviously we can only postulate on this matter; our short study offers no findings on this topic. However, it is clearly evident that one's identity and sense of self will change over the course of a lifetime, and that narratives pertaining to the same set of images might be realised through different sites of expression at different points in time. Thus, in the design of lifelogging technologies, it is important to recognise that what seemed relevant at the time of image capture might be overshadowed by different topics at a later date; the ways in which images are interpreted and repurposed will alter. Indeed, it seems extremely likely that as children grow, their take on SenseCam data streams as uninteresting may become considerably different. The current mechanism of storing SenseCam images, in which the user bookmarks sequences of interest when they view them, does not cater for this.
Also related to the storage of lifelog images, this study has shown that the automaticity of SenseCam seemed to result in a sense that no one person owned the photos. Family members watched back one another's image streams with interest (for example, in one of the interview extracts presented, a mother talks about the insight she has gained into her partner's day). Additionally, for householders living together, aspects of one's life are also simultaneously logged by others. Observing one's interactions with a child via that child's SenseCam gives a different slant to the use of a lifelogging tool and allows new perspectives to be gained (see also [14]). Indeed, there seemed to be few boundaries between the SenseCam data streams of different family members, especially when these were captured during shared activities. While not wishing to underplay privacy issues (in fact, some householders did turn their SenseCams off on occasion, purportedly because these periods were too dull to record), it seems important to acknowledge that access to lifelog images should at times be open to select others, an approach that contrasts somewhat with current approaches to storing this type of data. How image streams might be combined, watched in parallel, or sections of interest found when the camera was worn by another, are all questions that may need to be addressed.

Having considered the implications of our study in the context of lifelogging, we will finish by pondering its meaning for technologies which support UGC. As Misztal [19] suggests, successful user narratives have various characteristics, including:

' $a$ beginning and an end, an interesting storyline and impressive heroes. The fact that memorizing is not free of social constraints and influences suggests the importance of another type of memory - namely, collective or social memory ...' ( $\mathrm{p}$. 10)

In the findings presented here we have considered examples of these narratives, highlighting how the integration of UGC, as produced by technologies such as SenseCam, into media production more generally, must attend to the way in which rough and ready images are transformed into more polished outcomes. These processes are shaped further by the interests of the different kinds of people who are engaged in undertaking them. We have shown here how the users of SenseCam are engaged in making their recordings into mini narratives, as illustrated by the ease with which they could find the potential for a (structured) narrative within the recording, and the imaginativeness with which they could realise that narrative in recognisable form.

However, this work does not take the forms that professional organisations typically produce. The narrative forms we describe most likely work against existing conventions of narrative - they are rawer, more piecemeal, and specifically occasioned. Media organisations might wish to make use of this type of data as part of the ongoing transformation between author and reader, or to innovate narrative forms which confront, subvert and disable established narrative convention. If they are to be successful in this, they will need to be aware of the quite different ways in which these home-made narratives are produced. With SenseCam, the unusually candid nature of the images and the capture of the everyday (including aspects of it not normally considered photoworthy [cf. 25]) highlights how recording the banal can also lead to surprises. However, our study has also emphasised a deeply personal orientation to the images: the sense of routine, the depressing fact that one spends so little time with one's children, or the tenderness expressed when noticing that one's partner holds one's hand 
while driving, all illustrate how the small stories that might be told through such a device are steeped in personal experience. It is perhaps unsurprising then, that when asked, our participants could see the potential of exploring SenseCam image streams captured at events, such as festivals, which they had also attended, but expressed little interest in simply perusing images associated with strangers. The craftsmanship needed to construct interesting narratives around such sequences must not be underestimated.

\section{CONCLUSION}

The design space surrounding SenseCam, we have argued, is constructed in complex ways. The 'reconstruction narratives' that we have described range from the banal to the profound; from the jokey to the powerfully serious. They arise at moments of great significance, occasioned in the use of the technology and the recounting of stories of family and friendship. At other times they do not, largely because the practical business of family and friendship obtrudes. Trying to understand better why the technology is sometimes used and sometimes not, and why it is appropriated in the various ways we refer to, means placing usage in this context of narrative, memory and practice. We suggested a need to pay attention both to the 'site of expression' (which has to do with what aspect of our lives we are looking at) and to 'performativity' (which has to do with the occasions upon which we construct narratives and the identity work that we do around it). In other words, making sense of SenseCam necessitates a consideration of the topic and how it is selected, as well as the performance, or identity work, that surrounds it. The two are closely interwoven, and are separated here only for analytic purposes.

By placing SenseCam in this context, we have attempted an exploration of what it is to be 'social' in a digitally-mediated age. We have seen how the small stories that were generated by our participants were linked to their social identity, or stage in family life, and how family members used images associated with one another to enable insight and reflection. It seems then, that in the context of entire households undertaking lifelogging, and doing so over the course of a lifetime, individuals will reorient to the data that is collected over time, and may wish to have access to photos that have been captured by others. We have highlighted some of the questions that this raises pertaining to rights of ownership, display, selection, use, and so on, while underlying the importance of personal insight when trying to interpret such data. In conclusion, if lifelogging technologies are to become ubiquitous, or are to be used in innovating new forms of media production, a careful consideration is needed when deciding how such data should be stored, accessed and portrayed.

\section{ACKNOWLEDGMENTS}

Thanks to Gavin Smyth, Steve Hodges and Emma Berry for help with SenseCam and its related software, and to the participants for their involvement. This research was conducted as part of Participate, TSB project No. TP/153421.

\section{REFERENCES}

[1] Baddeley, A.D. 1999. Essentials of Human Memory. Psychology Press Ltd., Hove.

[2] Brundage, W.F. 2000. Where These Memories Grow: History, Memory and Southern Identity. University of North Carolina Press, Chapel Hill.

[3] Connerton, P. 1989. How Societies Remember. Cambridge University Press, Cambridge.
[4] Crabtree, A., Rodden, R. and Mariani, J. Collaborating Around Collections: Informing the Continued Development of Photoware. In Proc. CSCW '04. ACM Press (2004), 396-405.

[5] Ebbinghaus, H. 1985. Memory: A Contribution to Experimental Psychology. Dover, New York.

[6] Fleck, R. and Fitzpatrick, G. In press. Teachers' and Tutors' Social Reflection around SenseCam Images. To appear in the International Journal of Human-Computer Studies.

[7] Frohlich, D., Kuchinsky, A., Pering, A., Don, A. and Ariss, S. Requirements for Photoware. In Proc. $C S C W$ '02. ACM Press (2002), 166-175.

[8] Halbwachs, M. 1941. la Topographie Legenderie de Evangiles en Teore Sainte (The Legendary Topography of the Gospels of the Holy Land). Presse de Universaires de France, Paris.

[9] Halbwachs, M. 1992. On Collective Memory. University of Chicago Press, Oxford.

[10] Harper, R., Randall, D., Smyth, N., Evans, C., Heledd, L. and Moore, R. The Past is a Different Place: They Do Things Differently There. In Proc. DIS '08. ACM Press (2008), 271-280.

[11] Harper, R., Randall, D., Smyth, N., Evans, C., Heledd, L. and Moore, R. Thanks for the Memory. In Proc. HCI 2007, Volume 2. British Computer Society (2007).

[12] Hodges, S., Williams, L., Berry, E., Izadi, S., Srinivasan, J., Butler, A., Smyth, G., Kapur, N. and Wood, K. SenseCam: A Retrospective Memory Aid. In Proc. UbiComp '06. Springer-Verlag (2006), 177-193.

[13] Lee, H., Smeaton, A.F., O'Connor, N.E., Jones, G.J.F., Blighe, M., Byrne, D., Doherty, A.R. and Gurrin, C. 2008. Constructing a SenseCam Visual Diary as a Media Process. Multimedia Systems Journal 14, (6) 341-349.

[14] Lindley, S.E., Randall, D., Glancy, M., Smyth, N. and Harper, R. Reflecting on oneself and on others: Multiple perspectives via SenseCam. Presented at the CHI 2009 workshop on Designing for Reflection on Experience.

[15] Lindley, S.E., Harper, R., Randall, D., Glancy, M. and Smyth, N. (in press). Fixed in Time and "time in motion": Mobility of Vision through a SenseCam Lens. To appear at MobileHCI '09.

[16] Ljungblad, S. Passive Photography from a Creative Perspective: "If I would just shoot the same thing for seven days, it's like... what's the point?" In Proc. CHI '08. ACM Press (2009), 829-838.

[17] Middleton, D. and Brown, D. 2005. The Social Psychology of Experience: Studies in Remembering and Forgetting. Sage, London.

[18] Middleton, D. and Edwards, D. 1990. Collective Remembering. Sage, London.

[19] Misztal, B.A. 2003. Theories of Social Remembering. Open University Press, Maidenhead.

[20] Neisser, U. and Hyman, E. 2000. Memory Observed: Remembering in Natural Contexts, $2^{\text {nd }}$ Ed. Worth, New York.

[21] Schacter, D. 2001. The Seven Sins of Memory: How the Mind Forgets and Remembers. Houghton Mifflin, Boston and New York. 
[22] Sellen, A.J., Fogg, A., Aitken, M., Hodges, S., Rother, C. and Wood, K. Do Life-Logging Technologies Support Memory for the Past? In Proc. CHI '07. ACM Press (2007), 81-90.

[23] Shirky, C. 2007. Here Comes Everybody: The Power of Organizing Without Organizations. Penguin Press, Hammondsworth.

[24] Tan, D., Sellen, A., Czerwinski, M., Bell, G., Gemmell, J., Wood, K., et al. 2007. Save Everything: Supporting Human Memory with a Personal Digital Lifetime Store. In Personal Information Management: Challenges and
Opportunities, J. Teevan and W. Jones, Eds. University of Washington Press, Seattle.

[25] Van House, N., Davis, M., Ames, M., Finn, M. and Viswanathan, V. The Uses of Personal Networked Digital Imaging: An Empirical Study of Cameraphone Photos and Sharing. In Ext. Abstracts CHI '05. ACM Press (2005), 1853-1856.

[26] Zerubavel, E. 1995. Recovered Roots: Collective Memory and the Making of Israeli National Tradition. University of Chicago Press, Chicago. 